\title{
Characterization of rice husk carbon produced through simple technology
}

\begin{abstract}
Textile wastewater contains different colors which are harmful to the environment. Activated carbon can be used for the decolorization of textile wastewater. Most of the textile plants in Bangladesh do not use the activated carbon due to its expensive cost and still it is classified as imported item. Low-cost activated carbon produced from locally available materials can solve this problem. This paper describes the color removal of textile wastewater by adsorption process using activated carbon derived from rice husk in a low-cost method. Thermal activation system was applied for the preparation of carbon. The maximum adsorption of color was found at an optimum temperature of $400 \mathrm{C}$ with the retention time of 60 minutes. Thus this study demonstrated encouraging performance of activated carbon produced from rice husk compared to the industrial grade activated carbon for decolorization of textile wastewater in the analysis.
\end{abstract}

Keyword: Activated carbon; Adsorption; Rice husk; Textile wastewater; Decolorization 